\title{
Unwanted pregnancies in Gauteng and Mpumalanga provinces, South Africa: Examining mortality data on dumped aborted fetuses and babies
}

R Jacobs, MA (Research Psychology); N Hornsby, MA (Research Psychology); S Marais, D Litt et Phil (Sociology of Health)

SAMRC-UNISA (South African Medical Research Council-University of South Africa) Violence, Injury and Peace Research Unit, Tygerberg, Cape Town, South Africa

Corresponding author: R Jacobs (roxanne.jacobs@mrc.ac.za and roxy.september01@gmail.com)

\begin{abstract}
Background. Across the world, millions of women unintentionally become pregnant and decide to terminate the pregnancy. Despite progressive abortion laws in South Africa (SA), evidence suggests that many women of all ages still resort to unsafe terminations outside legal, designated facilities. Media reports alert the public to an increase in the illegal dumping of fetuses and abandoned babies, suggesting an increase in unsafe termination practices as well as concealed births.

Objective. To examine mortality data to identify trends in the dumping of aborted fetuses and abandoned babies in SA

Method. This study utilised data from the National Injury Mortality Surveillance System in two provinces, namely Gauteng and Mpumalanga. A total sample of mortality data was used to analyse trends associated with this phenomenon from 2009 to 2011 . Descriptive, exploratory statistics were used and included the calculation of crude population incidence rates for abortions and abandoned babies as well as figures $(n)$ and percentages (\%) for each category under investigation.

Results. An increase in the rate of discovery of non-viable fetuses was noted for both provinces over the 3-year period, while there was a significant decrease in the discovery of deceased abandoned babies in Gauteng only.

Conclusion. The illegal dumping of fetuses and babies is a very real public health concern in both Gauteng and Mpumalanga. Information is insufficient for adequate surveillance, and improved data collection systems should be prioritised.

S Afr Med J 2014;104(12):864-869. DOI:10.7196/SAMJ.8504
\end{abstract}

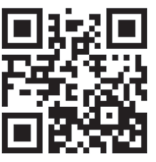

In 1999, a total of 210 million women became pregnant globally; 80 million of these pregnancies were reported to be unintentional. ${ }^{[1]}$ Poor or restricted access to contraceptive services ${ }^{[1]}$ and lack of social and financial support ${ }^{[2]}$ are some of the main reasons why women are faced with unintended pregnancies. Research has shown that women in South Africa (SA) experience considerable difficulties in negotiating safe sex practices. ${ }^{[2,3]}$ Women often face the realities of abuse, forced sex, and/or desertion when insisting on the use of condoms, a request that is stigmatised and interpreted as a sign of infidelity or admission to having a sexually transmitted disease. ${ }^{[3]}$ Poverty also plays a significant role in unwanted pregnancies where unfavourable economic and social circumstances can lead women to opt for an abortion, especially in the context of 'deepened economic hardships' associated with health concerns relating to HIV/AIDS. ${ }^{[2]}$ Young girls who partner with older men are identified as especially vulnerable to sexual exploitation owing to their financial dependency. They find that their access to and control over resources (or lack thereof) greatly influence the degree to which they are able to exercise their rights, especially with regard to having protected sex and the choice to terminate an unwanted pregnancy. ${ }^{[3]}$

\section{Unsafe abortion}

Abortion legislation varies from very conservative to liberal positions across the globe. Research shows that where legislation tends to be restrictive, abortion mortality and morbidity tend to be highest. $^{[4,5]}$ For example, where women seen as victims of circumstances are permitted to terminate a pregnancy (e.g. in cases of a medical emergency, fetal abnormality, rape or incest), others who do not meet these criteria are forced to seek alternatives that render them vulnerable to the dangers associated with illicit and unsafe abortion. According to the World Health Organization (WHO), abortions are deemed 'unsafe' when a procedure is 'characterised by the lack or inadequacy of skills of the provider, hazardous techniques and unsanitary facilities. ${ }^{[1]}$ In 1995, a total of 46 million women across the world voluntarily terminated their unwanted pregnancies. Of these terminations, 27 million were legal, with an estimated 19 million believed to have occurred outside the legal system. ${ }^{[6]}$ In 2003, almost half $(48 \%)$ of about 42 million abortions were reportedly unsafe, of which an alarming $97 \%$ were in developing countries. ${ }^{[6-8]}$ In the southern African region (including Botswana, Lesotho, Namibia, SA and Swaziland, of which SA forms the major component), 120000 unsafe abortions were estimated to have occurred in 2008. ${ }^{[9]}$

\section{Abortion in SA}

SA decriminalised abortion in 1996 by introducing the Choice on Termination of Pregnancy Act, ${ }^{[10]}$ which states that a pregnancy may be terminated up to 12 weeks' gestation at a woman's request. Termination from weeks 13 - 20 will only be allowed if a medical risk exists, the pregnancy is the result of rape or incest, or the pregnancy would adversely affect the woman's social or economic circumstances. The Act goes on to describe the circumstances under which a pregnancy may be terminated after 20 weeks' gestation, who is legally permitted to perform these procedures, and under what physical conditions surgical termination may take place. Unlike 27 other countries, SA law also protects the individual choice of minors. ${ }^{[4]}$ Minors are encouraged to consult with their parents, guardians, family and friends; however, should they choose 
not to, they may not be denied these services and may terminate a pregnancy without parental consent. ${ }^{[10]}$

Despite these major developments in policy and legislation, since 1994 research has shown that women are still having abortions outside the designated facilities, even in areas where many formal services exist. ${ }^{[11]}$ Women have been found to prefer a quick, private response to their problem and to seek help ranging from the broader medical sector, which includes doctors, nurses, pharmacists and traditional healers, or resort to self-induced methods such as use of laxatives, medicines, household products and oral contraceptives. ${ }^{[1]}$ Hazardous methods such as these have been shown to lead to immediate, medium- and long-term complications including severe bleeding, infertility and even death. ${ }^{[12,13]}$

There are other explanations for why women opt for unsafe methods instead of utilising legitimate services. A WHO study in 2010 showed that about $30 \%$ of women in SA continue to believe that abortion is illegal. ${ }^{[12]}$ Many were found to lack knowledge about circumstances in which abortion can be performed or facilities that perform it. ${ }^{[11]}$ Those who knew about these services found them to be inaccessible and/or unacceptable, and reported that they feared staff rudeness, gossip and judgement. Furthermore, they had general concerns about their privacy, and were forced to seek alternatives (even illegal ones) because of long waiting lists for second-trimester terminations. ${ }^{[11]}$ Services are also disproportionately concentrated in major urban centres, particularly in Gauteng Province. ${ }^{[1]}$ Inaccessible or unacceptable services encourage women to seek alternatives that place them at risk.

\section{Illegal dumping of fetuses after abortions and abandoned babies}

Evidence of fetuses being illegally dumped has been found all over the world, ranging from those dumped illegally after legal abortions to those aborted and dumped outside the legal system. In 2010, a news report revealed that Thai police had found just over 2000 fetuses in a Buddhist temple morgue in Bangkok. ${ }^{[14]}$ Investigations later revealed that these abortions were illegally performed to circumvent Thailand's restrictive abortion laws, and that the fetuses were collected from various clinics all over the country and secretly cremated at regular intervals in the temple's furnace. ${ }^{[15]}$ In 2011, it was reported that legitimate abortion clinics in Texas, USA, were fined for illegally dumping aborted fetuses, ${ }^{[16]}$ and a year later boxes containing illegally aborted fetuses were found in a Russian forest. ${ }^{[17]}$ Media reports in SA are alerting the public to what is believed to be an increase in babies as well as fetuses being left in dustbins, gutters and dumps. ${ }^{[18-20]}$ These discoveries are often made by random strangers such as garbage collectors and pedestrians, who then alert the authorities. Although there is no research on which to base their claims, media reports offer poverty, teen pregnancies, rape, incest and unemployment as being at the root cause of dumping of newborns and fetuses. With the exception of a study that investigated why women are still having abortions outside designated abortion facilities, ${ }^{[11]}$ research related to unsafe reproductive practices in SA tends to focus on the legislative environment and unsafe abortions, ${ }^{[3,21-23]}$ as well as barriers to service delivery in the reproductive health sector. ${ }^{[24-26]}$ No research was found that specifically investigates the phenomenon of dumping babies and fetuses, which represent concealed births and abortions.

\section{Objective}

The purpose of this study was to examine mortality data to determine whether the illicit dumping of non-viable fetuses (defined as the remains of aborted fetuses that are found and recorded in the National Injury Mortality and Surveillance System (NIMSS)) and abandoned babies (defined as the remains of full-term newborns that died as result of abandonment and are recorded in the NIMSS) are indeed increasing, as is reported in SA media.

\section{Methods}

The study utilised data from the NIMSS and reports trends in fatalities of all deaths in two of the country's provinces, namely Gauteng (predominantly urban) and Mpumalanga (predominantly rural). This system has coverage of nine out of ten mortuaries (it excludes Pretoria mortuary) in Gauteng as well as all 19 mortuaries in Mpumalanga. The NIMSS was first established in 1999 and collects information from Forensic Pathology Services and State Forensic Chemistry laboratories using a single data form that is filled in for every deceased person entering each facility. It incorporates information from postmortem reports, SA Police 180 forms, chemical pathology laboratory results, and criminal justice system reports on a total of 21 items.

For the purposes of our investigation, descriptive, exploratory statistics were utilised to investigate the trends associated with the illegal dumping of fetuses in a densely populated urban area characterised by improved infrastructure (Gauteng), as well as a less populated rural area with limited infrastructure (Mpumalanga). Data analysis included the calculation of crude population incidence rates for cases of abortion and abandoned babies, as well as figures $(n)$ and percentages (\%) for each category under investigation. No distinction was made between males and females, as gender and any associated implications were not investigated. Likewise, gestation/age of the fetuses/babies was not included in these analyses, as this information currently simply does not exist. For the above reasons, population rates were not adjusted for age and gender, and only crude population rates were reported.

The NIMSS currently captures abortions and stillbirths as one category and has a separate category for abandoned babies. In order to ensure a sample representative of our interest, all reported cases of natural death were therefore excluded from our analysis on the assumption that this would also exclude any stillbirth cases from the dataset. Analysis comprised preliminary descriptive statistics investigating differences in reporting rates, total numbers of cases and percentages in each province, as well as between the two provinces. In terms of inferential statistics, $\chi^{2}$ analyses were performed to investigate statistical significance of within-group differences (i.e. differences within each province). Between-group analyses were not performed, as the two provinces were too disparate in sample size to allow for meaningful comparison. Areas analysed included external cause of injury (i.e. the circumstance under which the injury occurred), scene of injury (the place or scene where the actual injury occurred) and other scenes of injury (includes additional places where injury occurred that are not categorised under scene of injury) for further assessment of other, additional places of injury. All terms and descriptions for categories in the current study are in accordance with the definitions used by the NIMSS reporting system.

\section{Results}

This section reports on the external cause and scenes of injury for Gauteng and Mpumalanga provinces for the period 2009 - 2011.

\section{External cause of injury}

Overall comparisons

When data from 2009 to 2011 were aggregated, figures for deaths due to abortion were noticeably higher than for deaths attributed 


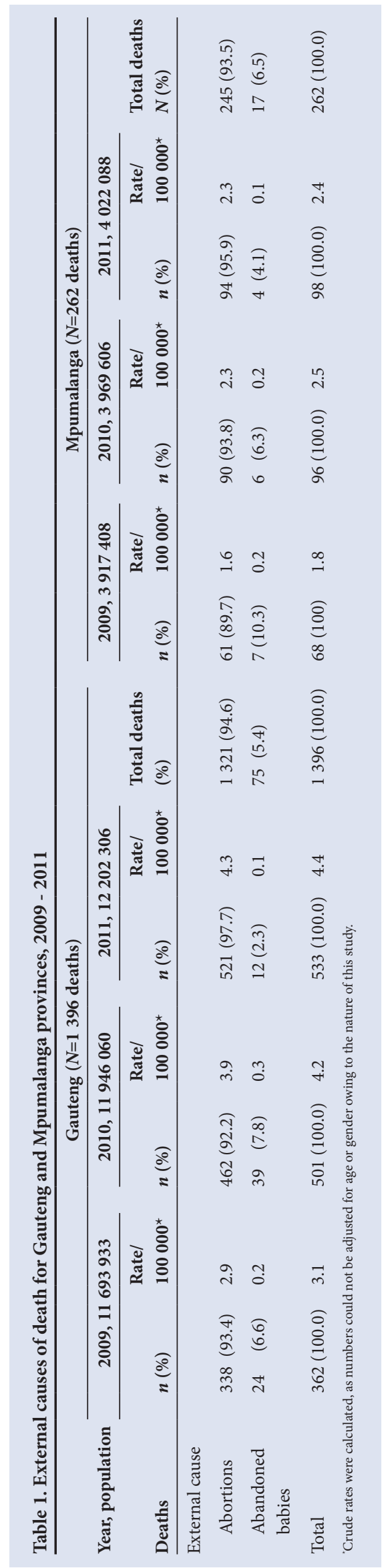

to abandonment of babies in both Gauteng and Mpumalanga (Table 1). For Gauteng, abortions ( $n=1$ 321, 94.6\%) resulted in significantly more deaths than abandonment ( $n=75,5.4 \%$ ). Similarly, for Mpumalanga there were more abortionrelated deaths ( $n=245,93.5 \%)$ than deaths following abandonment $(n=17,6.5 \%)$.

\section{Comparisons by year}

With disaggregation of figures across the years (Table 1), the death rates for abortions show a steady increase for Gauteng (2009: rate 2.9/100 000; 95\% confidence interval (CI) 2.58 - 3.20; 2010: 3.9/100 000; $95 \%$ CI $3.51-4.22$; 2011: 4.3/100 000; $95 \%$ CI $3.90-4.64$ ), while the rate for Mpumalanga increased between 2009 and 2010 (1.6/100 000; 95\% CI 1.17 - 1.95 and 2.3/100 000; 95\% CI 1.80 - 2.74, respectively), but remained constant between 2010 and 2011 (2011: 2.3/100 000; $95 \%$ CI 1.86 - 2.81). The death rate for abandoned babies in Gauteng, on the other hand, declined between 2010 $(0.3 / 100000 ; 95 \%$ CI $0.22-0.43)$ and 2011 (0.1/100 000; 95\% CI $0.04-0.15)$, as it did in Mpumalanga (2010: 0.2/100 000; 95\% CI 0.03 - 0.27; 2011: 0.1/100 000; $95 \%$ CI $0.00-0.20$ ).

Analyses of differences between the years were performed at both the conventional significance level $(p=0.05)$ and the adjusted significance level $(p=0.01)$ to minimise family-wise type I error. Only Gauteng showed significant differences in abandonment-related deaths across the 3 years at both significance levels. At $p=0.05$, for Gauteng the increase in deaths due to abandonment in $2010(n=39,52.0 \%)$ and the decrease in deaths due to abandonment in $2011(n=12,16.0 \%)$ were found to be statistically significant $\left(\chi^{2}\right.$ (2 degrees of freedom, $N=1396)=17.07 ; p<0001)$. At the adjusted $p=0.01$, only the decrease in deaths due to abandonment in 2011 was found to be significant.

\section{Scenes of injury}

For scenes of injury (including other scenes of injury), analyses were performed on an aggregate of both abortions and abandoned babies. The phenomenon of illegal dumping of babies and fetuses and its association with certain scenes of injury were of specific interest. From 2009 to 2011 the top three scenes of injury in Gauteng were roads $(n=325,23.3 \%)$, open land $(n=287,20.6 \%)$ and 'place unknown' $(n=206,14.8 \%)$. Comparisons by year show that roads were the leading scene of injury for $2010(n=120,24.0 \%)$ and
2011 ( $n=134,25.1 \%)$, while open land was the leading scene of injury in 2009 ( $n=74$, 20.4\%) (Table 2).

A different profile emerged for Mpumalanga, where the leading scene of injury was 'place unknown' ( $n=66,25.2 \%)$, followed by 'other' $(n=45,17.2 \%)$ and private house $(n=27,10.3 \%)$. On year-specific analysis, the leading scene of injury for 2009 was 'place unknown' $(n=34,50.0 \%)$, for 2010 'other' ( $n=25,26.0 \%)$, and for 2011 informal settlements ( $n=23,23.5 \%)$ (Table 2).

\section{Other scenes of injury}

Analysis of other scenes of injury provided seven additional scenes of injury for Gauteng, including cemetery, dump site, military base, public toilet, rubbish bin and sewer/drain (both included in this category), with only dump site and sewer/drain for Mpumalanga. For Gauteng, dump sites remained the most common other scene of injury for 2009 $(n=10,50.0 \%), 2010(n=10,41.7 \%)$ and 2011 $(n=49,59.0 \%)$ followed by sewer/drain sites in $2009(n=6,28.6 \%), 2010(n=9,37.5 \%)$, and $2011(n=25,30.1 \%)$.

In contrast to Gauteng, in Mpumalanga sewers/drains were the most common site for illegal dumping of babies and fetuses for $2009(n=5,83.0 \%), 2010 \quad(n=14,56.0 \%)$ and $2011(n=13,71.0 \%)$. The number of babies dumped in cemeteries showed a marked increase between $2009(n=1,17.0 \%)$ and $2010(n=11,44.0 \%)$, with a decline in $2011(n=1,29.0 \%)$ (Table 3). For 2010, the difference between numbers of babies dumped in cemeteries v. sewers/drains ( $n=11,44.0 \%$ and $n=14,56.0 \%$ respectively) was not as pronounced as in other years.

\section{Discussion}

The evidence presented here reveals that the illegal dumping of fetuses and babies is a real public health concern in both Gauteng and Mpumalanga provinces. Our study revealed that there was an increase in the rate of discovery of non-viable fetuses in both provinces over the 3-year period, while at the same time there was a slight decrease in discoveries of deceased, abandoned babies. The first of these findings suggests that more people are discovering the remains of illicit abortions, indicating a possible increase in this phenomenon. When inferential testing was used, only Gauteng produced significant changes in the number of cases of death due to abandonment reported between 2009 and 2011, with a statistically significant increase in 2010 and a significant decrease in 2011. The decrease may be attributed to various factors, such as an increase in media attention to the baby/fetus dumping 
Table 2. Top ten scenes of injury ${ }^{\star}$ for Gauteng and Mpumalanga provinces, 2009 - 2011

\begin{tabular}{|c|c|c|}
\hline & $n$ & $\%$ \\
\hline \multicolumn{3}{|l|}{ Gauteng ( $N=1396)$} \\
\hline \multicolumn{3}{|l|}{2009} \\
\hline Open land/beaches & 74 & 20.4 \\
\hline Roads & 71 & 19.6 \\
\hline Place unknown & 68 & 18.8 \\
\hline Private house/yard & 39 & 10.8 \\
\hline Informal settlement & 22 & 6.1 \\
\hline Other & 20 & 5.5 \\
\hline Residential institute & 17 & 4.7 \\
\hline Lake/river/dam & 14 & 3.9 \\
\hline Countryside & 11 & 3.0 \\
\hline Amusement park/sports area & 7 & 1.9 \\
\hline \multicolumn{3}{|l|}{2010} \\
\hline Roads & 120 & 24.0 \\
\hline Open land/beach & 117 & 23.4 \\
\hline Place unknown & 100 & 20.0 \\
\hline Private house/yard & 32 & 6.4 \\
\hline Informal settlement & 30 & 6.0 \\
\hline Other & 24 & 4.8 \\
\hline Residential institute & 20 & 4.0 \\
\hline Countryside & 13 & 2.6 \\
\hline Lake/river/dam & 10 & 2.0 \\
\hline Railway & 9 & 1.8 \\
\hline \multicolumn{3}{|l|}{2011} \\
\hline Roads & 134 & 25.1 \\
\hline Open land/beach & 96 & 18.0 \\
\hline Other & 83 & 15.6 \\
\hline Private house/yard & 46 & 8.6 \\
\hline Informal settlement & 40 & 7.5 \\
\hline Place unknown & 38 & 7.1 \\
\hline Residential institute & 27 & 5.1 \\
\hline Lake/river/dam & 16 & 3.0 \\
\hline Industrial/construction area/mine & 15 & 2.8 \\
\hline Railway & 11 & 3.1 \\
\hline \multicolumn{3}{|l|}{ Mpumalanga $(N=262)$} \\
\hline \multicolumn{3}{|l|}{2009} \\
\hline Place unknown & 34 & 50.0 \\
\hline Other & 6 & 8.8 \\
\hline Roads & 5 & 7.4 \\
\hline Industrial/construction area/mine & 5 & 7.4 \\
\hline Open land/beach & 5 & 7.4 \\
\hline Private house/yard & 4 & 5.9 \\
\hline Residential institute & 4 & 5.9 \\
\hline School/educational area & 1 & 1.5 \\
\hline
\end{tabular}

Table 2. (continued) Top ten scenes of injury ${ }^{\star}$ for Gauteng and Mpumalanga provinces, 2009 - 2011

\begin{tabular}{|c|c|c|}
\hline & $n$ & $\%$ \\
\hline Medical service area & 1 & 1.5 \\
\hline Farm/primary production area & 1 & 1.5 \\
\hline \multicolumn{3}{|l|}{2010} \\
\hline Other & 25 & 26.0 \\
\hline Place unknown & 19 & 19.8 \\
\hline Open land/beach & 11 & 11.5 \\
\hline Industrial/construction area/mine & 9 & 9.4 \\
\hline Private house/yard & 8 & 8.3 \\
\hline Roads & 8 & 8.3 \\
\hline Residential institute & 6 & 6.3 \\
\hline Farm/primary production area & 3 & 3.1 \\
\hline Amusement park/sports area & 2 & 2.1 \\
\hline Informal settlement & 2 & 2.1 \\
\hline \multicolumn{3}{|l|}{2011} \\
\hline Informal settlement & 23 & 23.5 \\
\hline Private house/yard & 15 & 15.3 \\
\hline Other & 14 & 14.3 \\
\hline Place unknown & 13 & 13.3 \\
\hline Open land/beach & 10 & 10.2 \\
\hline Roads & 4 & 4.1 \\
\hline Industrial/construction area/mine & 4 & 4.1 \\
\hline Lake/river/dam & 3 & 3.1 \\
\hline Residential institute & 2 & 2.0 \\
\hline Railway & 2 & 2.0 \\
\hline
\end{tabular}

phenomenon ${ }^{[18-20]}$ and the introduction of 'baby safes' across the country (that provide a safe place where unwanted babies can be dropped off anonymously). ${ }^{[19,27]}$ Our finding that differences were only significant in Gauteng may be attributable solely to that province's larger population compared with Mpumalanga, and does not in any way indicate that this problem is not significant in Mpumalanga. The decline noted may not conclusively prove a decrease in this phenomenon per se, but rather indicate that fewer babies were found dead after being abandoned during the period of investigation, as opposed to being found alive and rescued. For these reasons, there is a need for more rigorous, scientific investigation into the illicit dumping of fetuses and babies.

Where scenes of injury were known, the commonest scenes for Gauteng were roads and open land, whereas for Mpumalanga they were 'place unknown' and 'other', among which sewers/drains and dump sites were most often used. These places are accessible by the public and provide a degree of anonymity.

The increase in the phenomenon of dumping in both provinces is indicative of the following. Firstly, the need for secrecy is outweighing the risks involved in seeking an unsafe abortion. Some women who use unsafe methods seek options that offer a quick and private response to their situation, while others wish to avoid the perceived poor-quality healthcare in hospitals. ${ }^{[11]}$ Lack of access to acceptable healthcare services places women of all ages at risk of negative health consequences, including serious morbidity, risk of 
Table 3. Other scenes of injury for Gauteng and Mpumalanga provinces, 2009 - 2011

\begin{tabular}{|c|c|c|c|c|c|c|c|c|c|c|c|c|}
\hline \multirow[b]{3}{*}{ Other scenes of injury } & \multicolumn{6}{|c|}{ Gauteng } & \multicolumn{6}{|c|}{ Mpumalanga } \\
\hline & \multicolumn{2}{|c|}{2009} & \multicolumn{2}{|c|}{2010} & \multicolumn{2}{|c|}{2011} & \multicolumn{2}{|c|}{2009} & \multicolumn{2}{|c|}{2010} & \multicolumn{2}{|c|}{2011} \\
\hline & $n$ & $\%$ & $n$ & $\%$ & $n$ & $\%$ & $n$ & $\%$ & $n$ & $\%$ & $n$ & $\%$ \\
\hline Cemetery & 0 & 0 & 1 & 4.2 & 1 & 1.2 & 1 & 17.0 & 11 & 44.0 & 13 & 7.0 \\
\hline Dump site & 10 & 50.0 & 10 & 41.7 & 49 & 59.0 & 0 & 0 & 0 & 0 & 0 & 0 \\
\hline Military base & 1 & 5.0 & 1 & 4.2 & 0 & 0 & 0 & 0 & 0 & 0 & 0 & 0 \\
\hline Public toilet & 2 & 10 & 1 & 4.2 & 5 & 6.0 & 0 & 0 & 0 & 0 & 0 & 0 \\
\hline Rubbish bin & 1 & 5.0 & 2 & 8.3 & 3 & 3.6 & 0 & 0 & 0 & 0 & 0 & 0 \\
\hline Sewer/drain & 6 & 28.6 & 9 & 37.5 & 25 & 30.1 & 5 & 83.0 & 14 & 56.0 & 32 & 93.0 \\
\hline Total & 20 & 100.0 & 24 & 100.0 & 83 & 100.0 & 6 & 100.0 & 25 & 100.0 & 45 & 100.0 \\
\hline
\end{tabular}

future infertility and death, ${ }^{[12,13,28]}$ as well as endangering the lives of full-term babies who are abandoned after a concealed birth. Secondly, despite an increase in designated facilities providing reproductive health services as well as attempts to create a public service environment that is accessible to women of all ages, ${ }^{[25]}$ an undisclosed population of women affected by unwanted pregnancies are not able to rely on the available services. This is believed to be a result of lack of information, perceived poor quality of services, ${ }^{[11]}$ and women being misinformed by hospital staff regarding services and legislation. ${ }^{[2]}$ Furthermore, women who are able to access these services, despite existing limitations, are often stigmatised and report facing judgemental attitudes from service providers. ${ }^{[3]}$ Accessibility to services is further limited by our finding that more than half the designated facilities that are registered providers of termination services are in reality not providing this service. ${ }^{[23]}$ This reflects an unwillingness of healthcare workers to be trained to undertake termination of pregnancy. ${ }^{[23]}$

Since no research has investigated the persons involved in the dumping of fetuses and babies, the best we can do at this stage is to rely on proxies identified by previous research to indicate who these vulnerable groups could be, namely young women and women vulnerable to circumstances of poverty, unemployment and financial dependence, as well as a lack of social and financial support. ${ }^{[3]}$ Our findings indicate that there is a need for comprehensive, detailed surveillance of this phenomenon, including information on the remains discovered and circumstances surrounding the deaths, as well as information about the mothers and fathers of dumped babies and fetuses. The latter represents a considerable challenge.

\section{Conclusion}

This study supports existing evidence that unsafe abortions remain a major concern in SA despite significant developments in the country's legislation and reproductive health environment. ${ }^{[5,22,23]}$ It furthermore suggests that women in all age groups: $(i)$ are in need of reproductive health education and support to prevent unwanted pregnancies; (ii) may be unaware of progressive legislation and services in SA; (iii) may be unfamiliar with alternatives (e.g. adoption services); and (iv) may not know how and where to access services. Despite legal reform and improved access to and knowledge of services, the termination of unwanted pregnancies in Gauteng and Mpumalanga provinces may be highly stigmatised hence the overwhelming need for secrecy. There is a need to prioritise the development of initiatives and health promotion activities that not only identify particularly vulnerable groups but also specifically tailor policy responses and programme interventions to meet the needs of those vulnerable to these clandestine practices. Since women's negotiating power in safe sex practices remains a concern, state attempts to increase the availability and accessibility of reproductive health services should include a focus on men as partners who share responsibility for decisions regarding reproductive health choices. Surveillance of this public health concern is currently inadequate, and improved data collection systems should be prioritised. Future investigations should be geared towards developing appropriate strategies aimed at the prevention of illegal dumping of fetuses and abandoned babies.

\section{Study limitations}

Because the NIMSS provides coverage only for Gauteng and Mpumalanga, analysis was limited to these two provinces. Owing to the limitations of the NIMSS, cases from the Pretoria mortuary were not included and the nature of the data limited analyses to withinprovince comparison. The lack of data available on the gestation/ age of fetuses/babies dumped limited the scope of the analysis. Even though natural deaths were excluded, the possibility exists that some stillbirth cases were unavoidably included in the analysis. This is because some stillbirths may be recorded as 'undetermined' instead of 'natural' when the case is still under police investigation (Prof. Jeanine Vellema, personal communication, January 2014; Ms Janneate van Dyk, personal communication, December 2013). Another limitation is the possibility that the remains of legally aborted fetuses/stillbirths are handed back to the mother/family for burial, who incorrectly dispose of the remains (Ms Mariette Smith, personal communication, February 2014). The data needed to identify or distinguish these cases do not exist, so they would be included in our analysis. Finally, discrepancies were noted in how scenes of injury were recorded. In some instances, data capturers applied the correct definition for this category and identified it as 'place unknown', whereas others indicated it as the scene where the remains were found. There is a need for greater clarity in the current NIMSS and for distinction between scene of injury and where the remains were in fact discovered. We therefore recommend that a 'scene of discovery' category be created for a more accurate reflection of the true nature of the data.

Acknowledgements. We thank Prof. Jeanine Vellema and Ms Janneate van Dyk of the Gauteng and Mpumalanga forensic pathology services for providing clarification surrounding NIMSS data, and Ms Mariette Smith and Prof. Kopano Ratele for their insights. 


\section{References}

1. Fawcus SR. Maternal mortality and unsafe abortion. Best Pract Res Clin Obstet Gynaecol 2008;22(3):533-548. [http://dx.doi.org/10.1016/j.bpobgyn.2007.10.006]

2. Orner P, de Bruyn M, Cooper D. 'It hurts, but I don't have a choice, I'm not working and I'm sick' Decisions and experiences regarding abortion of women living with HIV in Cape Town, South Africa. Culture Health Sex 2011;13(7):781-795. [http://dx.doi.org/10.1080/13691058.2011.577907]

3. Varkey SI, Fonn S, Kethapile M. The role of advocacy in implementing the South African abortion law. Reprod Health Matters 2000;8(16):103-111. [http://dx.doi.org/10.1016/S0968-8080(00)90192-7] Berer M. Making abortions safe: A matter of good public health policy and practice. Reprod Health Matters 2002;10(19):31-44. [http://dx.doi.org/10.1016/S0968-8080(02)00021-6]

5. Jewkes R, Rees H, Dickson K, Brown H, Levin J. The impact of age on the epidemiology of incomplete abortions in South Africa after legislative change. BJOG 2005;112(3):355-359. [http://dx.doi. org/10.1111/j.1471-0528.2004.00422.x

6. Shah I, Ahman E. Age patterns of unsafe abortion in developing country regions. Reprod Health Matters 2004;12(24):9-17. [http://dx.doi.org/10.1016/S0968-8080(04)24002-2]

7. Sedgh G, Henshaw S, Singh S, Ahman E, Shah I. Induced abortion: Estimated rates and trend worldwide. Lancet 2007;370(9595):1338-1345. [http://dx.doi.org/10.1016/S0140-6736(07)61575-X]

8. Ahman E Shah I Unsafe abortion: Worldwide estimates for 2000. Reprod Health Matters 2002;10(19):13-17. [http://dx.doi.org/10.1016/S0968-8080(02)00012-5]

9. World Health Organization. Global and Regional Estimates of the Incidence of Unsafe Abortion and Associated Mortality in 2008. 6th ed. Geneva: World Health Organization, 2011. http://www. whalibdoc,whoint/publications/2011/9789241501118eng pdf?ua=1 (accessed 13 February 2014).

0. Choice on Termination of Pregnancy Act, No. 92 of 1996. http://www.parliament.gov.za/live/ commonrepository/Processed/20110729/67169_1.pdf (accessed 29 October 2014).

1. Jewkes RK, Gumede T, Westaway MS, Dickson K, Brown H, Rees H. Why are women still aborting outside design dx.doi.org/10.1111/j.1471-0528.2005.00697.x]

2. Osman S, Thompson A. A preventative pandemic: Unsafe abortion in South Africa. South Africa: Marie Stopes, 2012. http://www.ngopulse.org/category/tags/marie-stopes (accessed 24 December 2013).

3. Grimes DA, Benson J, Singh S, et al. Unsafe abortion: The preventable pandemic. Lancet 2006.368(9550):1908-1919. [http.//dx doi org/10.1016/\$0140-6736(06)69481-6].

14. BBC News. Thailand police find 2,000 foetuses in temple. Thailand: BBC-news Asia-Pacific, 2010. http://www.bbc.co.uk/news/world-asia-pacific-11785333 (accessed 26 July 2013).

15. Cohen E. Fetuses in a Thai Buddhist temple as chaotic irruption and public embarrassment. Asian Cohen E. Fetuses in a Thai Buddhist temple as chaotic irruption and public emb
Anthropol 2012;11(1):1-20. [http://dx.doi.org/10.1080/1683478X.2012.10600851]

6. Jones I. Texas abortion clinics fined for illegal dumping of aborted fetuses. USA: Examiner.com, 2011. http://www.examiner.com/article/texas-abortion-clinics-fined-for-illegal-dumping-of-aborted-
2. fetuses (accessed 26 July 2013)
17. UPI.com. Fetuses dumped illegally in Russian forest. Russia: UPI Top News, 2012. http://www. upi.com/Top_News/World-News/2012/08/03/Fetuses-dumped-illegally-in-Russian-forest/UPI78691344017060/ (accessed 26 July 2013).

18. News24. Dumping of babies increasing. Johannesburg: News24, 2010. http://www.news24.com/ SouthAfrica/News/Dumping-of-babies-increasing-20101104 (accessed 26 July 2013).

19. Farber T. Baby dumping on the rise in W Cape. Cape Town: IOL-news, 2012. http://www.iol.co.za/ news/south-africa/western-cape/baby-dumping-on-the-rise-in-w-cape-1.1267814\#.Uo4Q-NIW2Q (accessed 22 November 2013).

20. Child K, Hosken G. Born to be dumped. Gauteng: Times Live, 2012. http://www.timeslive.co.za/ local/2012/05/29/born-to-be-dumped (accessed 22 November 2013).

21. Buchmann E, Kunene B, Pattinson R. Legalized pregnancy termination and septic abortion mortality in South Africa. Int J Gynaecol Obstet 2008;101(2):191-192. [http://dx.doi.org/10.1016/j. ijgo.2007.10.017

22. Meel BL, Kaswa RP. The impact of the Choice on Termination of Pregnancy Act of 1996 (Act 92 of 1996) on criminal abortions in the Mthatha area of South Africa African Journal of Primary Health Care \& Family Medicine 2009;1(1):79-81. [http://dx.doi.org/10.4102/phcfm.vli1.36]

23. Cooper D, Morroni C, Orner P, et al. Ten years of democracy in South Africa: Documenting transformation in reproductive health policy and status. Reprod Health Matters 2004;12(24):70-85. [http://dx.doi.org/10.1016/S0968-8080(04)24143-X]

24. Jewkes RK, Abrahams N, Muo Z. Why do nurses abuse patients? Reflections from South African obstetric 9536(98)00240-8]

25. Department of Health. An Evaluation of the Implementation of the Choice on Termination of Pregnancy Act. South Africa: National Department of Health, 2000. http://www.doh.gov.za/docs/ reports/2000/abortion01.pdf (accessed 22 November 2013).

26. Trueman KA, Magwentshu M. Abortion in progressive legal environment: The need for vigilance in protecting and promoting access to safe abortion services in South Africa. Am J Public Health in protecting and promoting access to safe abortion services in $\mathrm{S}$.

27. Maclean S. New scheme in South Africa allows mothers to dump unwanted newborns in "baby safe' mounted on a wall. South Africa: Mail Online, 2011. http://www.dailymail.co.uk/news/ safe mounted on a wall. South Africa: Mail Online, 2011 . http://www.dalymail.co.uk/news/
article-1385510/Unwanted-South-African-babies-dumped-baby-safe-mounted-wall-streetcontroversial-new-scheme.html (accessed 22 November 2013).

28. Singh S. Hospital admissions resulting from unsafe abortion: Estimates from 13 developing countries. Lancet 2006;368(9550):1887-1892. [http://dx.doi.org/10.1016/\$0140-6736(06)69778-X]

Accepted 18 July 2014 